\title{
Effect of colloidal bismuth subcitrate on symptoms and gastric histology in non-ulcer dyspepsia. A double blind placebo controlled study
}

\author{
J Y Kang, H H Tay, A Wee, R Guan, M V Math, I Yap
}

\begin{abstract}
The aim of this study was to determine the effect of colloidal bismuth subcitrate (De Nol) on symptoms and gastric histology in patients with non-ulcer dyspepsia. In a single centre trial, patients with food related upper abdominal pain not caused by ulcer disease were randomised to receive one tablet of colloidal bismuth subcitrate or matching placebo four times daily for eight weeks. Seventy three patients were entered and 51 completed the trial: 28 patients in the colloidal bismuth subcitrate group and 23 in the placebo group. Overall there was no difference between the two groups in terms of symptom relief. Among patients with histological gastritis $(n=23)$, however, those who took colloidal bismuth subcitrate used fewer antacid tablets (for three of four fortnightly periods) and were more likely to become asymptomatic (eight of $11 v$ three of 12, p <0.05); their gastritis was more likely to resolve (five of $10 v 0$ of $12, \mathrm{p}<0.025$ ) and their gastric biopsies more likely to become negative for Helicobacter like organisms (eight of nine $v$ 0 of $12, p<0.001$ ) when compared with patients taking placebo. In contrast, patients who did not have gastritis in their index biopsies $(n=28)$ fared similarly whether they received colloidal bismuth subcitrate or placebo. Our results indicate that the administration of colloidal bismuth subcitrate benefited non-ulcer dyspepsia patients with gastritis but had no effect on those without.
\end{abstract}

Division of

Gastroenterology, Department of Medicine, National University Hospital, Singapore J Y Kang

H H Tay

R Guan

M V Math

I Yap

Department of Pathology, National University Hospital, Singapore A Wee

Correspondence to: Associate Professor J Y Kang, Division of Gastroenterology, of Gastroenterology, National University Hospital Lower Kent Ridge Road, Singapore 0511.

Singapore 0511 .

27 June 1989

Therapeutic trials on non-ulcer dyspepsia have yielded conflicting results to date. This is in part a problem of definition. Non-ulcer dyspepsia is probably a heterogeneous condition including different subsets of patients with different underlying pathophysiological mechanisms. One possible cause of non-ulcer dyspepsia is gastritis. Traditionally, gastritis is thought not to be a cause of symptoms.' Since the association between gastritis and Helicobacter pylori became established, ${ }^{2}$ however, oral colloidal bismuth subcitrate has been found to suppress these organisms and at the same time improve histological gastritis. ${ }^{3-5}$ Helicobacter pylori and histological gastritis are known to occur in approximately half of all patients with non-ulcer dyspepsia. ${ }^{67}$ The aim of the present study was to investigate the effect of colloidal bismuth subcitrate in a carefully selected group of non-ulcer dyspepsia patients with and without histological gastritis with regard to symptoms, gastric histology and the presence of Helicobacter like organisms.

\section{Methods}

PATIENT SELECTION

Patients with a history of dyspepsia for at least four weeks were admitted to the study after an index endoscopy had excluded the presence of peptic ulcer, gastric neoplasm or reflux oesophagitis. Dyspepsia was defined as upper abdominal pain or discomfort with at least two of the following three characteristics present: (1) precipitation by hunger, (2) relief or exacerbation by food, and (3) relief by antacid. Patients with a past history of peptic ulcer, and those whose abdominal pains were related to defecation, ${ }^{8}$ were excluded. Abdominal ultrasound was performed when clinically indicated and patients who showed evidence of biliary or pancreatic pathology were excluded from the study.

\section{TRIAL DESIGN}

Within two days of the index endoscopy, each patient was allocated by a prerandomised code to treatment with one tablet of colloidal bismuth subcitrate (De-Nol, Gist-Brocades) or matching placebo four times daily for eight weeks. Each tablet was to be taken half an hour before the three main meals of the day and before retiring no food or drink being allowed for at least half an hour before and after the tablet was taken. The patients were instructed to chew each tablet thoroughly before swallowing. A supply of antacid tablets (Rennies, Nicholas Lab Ltd) each containing calcium carbonate $680 \mathrm{mg}$ and light magnesium carbonate pH Eur $80 \mathrm{mg}$, was also given for symptomatic relief of pain.

Patients were asked to record their symptoms and antacid usage using diary cards. Follow up was carried out at two, four, and eight weeks. At each attendance, the patient's symptoms were reviewed and counts of returned tablets undertaken. Repeat endoscopy was performed after eight weeks' treatment. At that time patients 
were asked whether their symptoms were worse, unchanged, improved, or totally disappeared.

\section{ENDOSCOPIC AND HISTOLOGICAL ASSESSMENT}

At endoscopy the gastric body and gastric antrum were assessed as normal or inflamed. The mucosa was said to be inflamed if erythema, petechiae and/or erosions were present. A previous assessment of interobserver variation of this grading system showed agreement between two observers in 337 of 356 observations (95\%). ${ }^{9}$

One gastric biopsy was taken from the body and one from the antrum during the pretreatment and the post treatment endoscopies. Histological gastritis was diagnosed and its severity scored according to McNulty et al. ${ }^{10}$ Mononuclear and polymorphonuclear infiltration were each graded zero to four. The inflammatory score was taken to be the sum of these two grades and if this was three or more, histological gastritis was said to be present. The presence or absence of Helicobacter like organisms was assessed using the haematoxylin and eosin as well as the Warthin-Starry stains. All biopsies were read by the same pathologist without knowledge of the patients' details. A blind review of 49 biopsies ( 24 antral and 25 body) by the same pathologist showed agreement in Helicobacter like organisms and inflammatory scores in $49 / 49$ cases (100\%) and $44 / 49$ cases $(90 \%)$ respectively. In all five instances in which intraobserver variation occurred for inflammatory scores single grade differences were involved.

\section{STATISTICAL AND ETHICAL}

CONSIDERATIONS

Categorical data was analysed by the $\chi^{2}$ test with Yates's correction, or the Fisher's exact test. Numerical data was analysed by the Wilcoxon's

TABLE I Patient characteristics

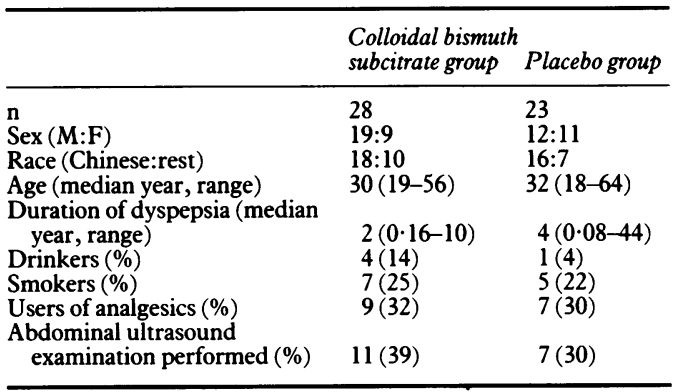

There was no significant difference between the two treatmen groups in any of the above parameters.

TABLE II Patients becoming asymptomatic over the trial period

\begin{tabular}{|c|c|c|c|}
\hline & $\begin{array}{l}\text { Colloidal bismuth } \\
\text { subcitrate group }\end{array}$ & Placebogroup & \\
\hline $\begin{array}{l}\text { All patients } \\
\mathrm{n} \\
\text { Number }(\%) \text { becoming asymptomatic }\end{array}$ & $\begin{array}{l}28 \\
13(46)\end{array}$ & $\begin{array}{l}23 \\
8(35)\end{array}$ & \\
\hline $\begin{array}{l}\text { Patients with histological gastritis in index biopsies } \\
\text { n } \\
\text { Number }(\%) \text { becoming asymptomatic }\end{array}$ & 11 & ${ }_{3}^{12}(25)$ & $\mathrm{p}<0.05$ \\
\hline $\begin{array}{l}\text { Patients with no histological gastritis in index biopsies } \\
\text { n } \\
\text { Number (\%) becoming asymptomatic }\end{array}$ & $17(29)$ & 11 & \\
\hline
\end{tabular}

rank-sum test. Probability values of less than 0.05 were considered significant.

The study was carried out in accordance with the Declaration of Helsinki. Informed consent was obtained from each patient.

\section{Results}

PATIENT CHARACTERISTICS (TABLE I)

Fifty one patients completed the study although three declined repeat endoscopy. Twenty eight patients received colloidal bismuth subcitrate while 23 were in the placebo group. There were no significant differences between the two groups with respect to sex, race, age, duration of dyspepsia, consumption of alcohol, tobacco, coffee or analgesics, and the numbers who had abdominal ultrasound examinations performed.

Repeat endoscopy was performed on day $56 \pm 4$ in 45 of the 48 patients. In the remainder, endoscopy took place on days 51,71 , and 72 respectively.

\section{SYMPTOM RESPONSE (TABLE II)}

Twenty one patients (41\%) became totally asymptomatic at the end of the study while 25 (49\%) reported partial improvement. Five patients $(10 \%)$ found that their symptoms remained unchanged. Overall there was no significant difference between the colloidal bismuth subcitrate group and the placebo group with regard to the proportions reporting improvement or to the proportions who became symptom free. Considering only the 23 patients who had gastritis in their index body and/or antral gastric biopsies, more patients in the colloidal bismuth subcitrate group reported total relief of symptoms when compared with patients taking placebo $(\mathrm{p}<0 \cdot 05)$. For patients without gastritis in their initial biopsies there was no difference between the two treatment groups with regard to the proportions becoming symptom free.

Among patients with gastritis in their index biopsies fewer antacid tablets were used in the colloidal bismuth subcitrate group than in the placebo group (Fig. 1). The differences reached statistical significance for the first three fortnights but not for the fourth. In contrast, there was no difference in antacid consumption between patients taking colloidal bismuth subcitrate and those taking placebo when histological gastritis was absent in the index biopsies (Fig. 2).

\section{ENDOSCOPIC APPEARANCES}

Sixteen of 27 patients (59\%) with endoscopic signs of mucosal inflammation of either the body or antrum or both at the index endoscopy had histological gastritis compared with seven of 24 patients $(30 \%)$ with normal endoscopic appearances. This difference failed to reach statistical significance $\left(\chi^{2}=3.51, p>0.05\right)$. Of the 16 patients with endoscopic and histological gastritis 14 had erythematous mucosa, another one had petechiae while erosions were found in the remaining one. Of the 11 patients with 


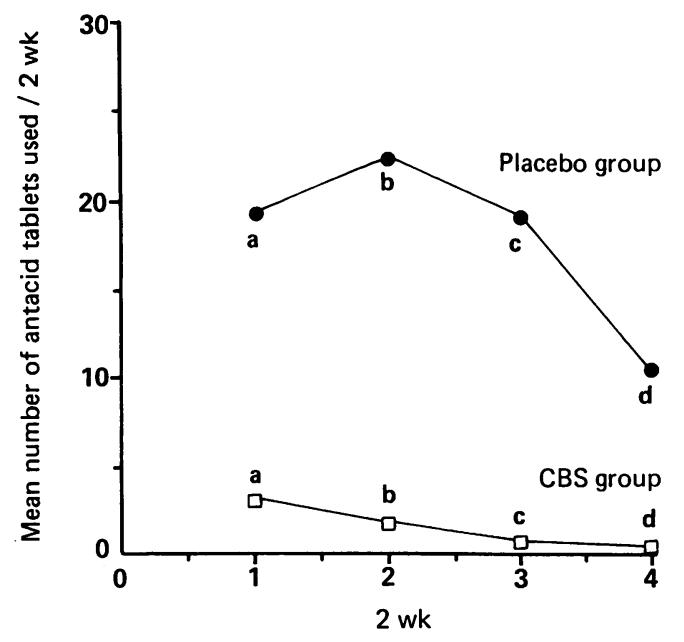

Figure 1: Use of antacids in patients with gastritis in their index biopsies, taking colloidal bismuth subcitrate or placebo. $a=p<0.02 ; b=p<0.02 ; c=p<0.025 ; d=n$.

endoscopic gastritis despite normal histological appearances eight showed only mucosal erythema: petechiae were present in two and erosions in one.

As stated earlier, three patients who completed the trial did not have repeat endoscopy. Gastroscopic findings became normal at repeat endoscopy for eight of 25 patients (32\%) who had endoscopic gastritis during their index examinations. Of the 23 patients with normal index endoscopies, endoscopic gastritis developed over the trial period in $10(43 \%)$. These changes in endoscopic findings were not influenced by whether the patients took colloidal bismuth subcitrate or placebo. Improvement or deterioration in endoscopic appearances was unrelated to symptomatic status at follow up. One of eight patients $(13 \%)$ who showed resolution of endoscopic gastritis became symptom free compared with three of $10(30 \%)$ who developed endoscopic gastritis over the trial period and 15/30 $(50 \%)$ whose endoscopic appearances remained unchanged.

\section{GASTRIC HISTOLOGY}

Adequate index gastric body biopsies were available for only 49 of the 51 patients who completed the study while adequate gastric antral biopsies were obtained in 50. Adequate repeat body biopsies were available for 44 patients: repeat antral biopsies for 46 .

INDEX BIOPSIES

Gastritis was present in $19 / 49$ (39\%) of index

TABLE III Reduction in inflammatory scores

\begin{tabular}{|c|c|c|c|c|c|c|}
\hline & \multicolumn{3}{|c|}{ Colloidal bismuth subcitrate group } & \multicolumn{3}{|c|}{ Placebo group } \\
\hline & Gastritis ${ }^{\star}$ & No gastritis ${ }^{\star}$ & All & Gastritis* & No gastritis ${ }^{\star}$ & All \\
\hline $\begin{array}{l}\text { Body biopsies } \\
\text { Score reduced } \\
\text { Score same or increased } \\
\text { Total }\end{array}$ & $\begin{array}{l}7 \\
2 \\
9\end{array}$ & $\begin{array}{r}3 \\
11 \\
14\end{array}$ & $\begin{array}{l}10 \\
13 \\
23\end{array}$ & $\begin{array}{r}5 \\
7 \\
12\end{array}$ & $\begin{array}{l}1 \\
8 \\
9\end{array}$ & $\begin{array}{r}6 \\
15 \\
21\end{array}$ \\
\hline $\begin{array}{l}\text { Antral biopsies } \\
\text { Score reduced } \\
\text { Score same or increased } \\
\text { Total }\end{array}$ & $\begin{array}{c}10+ \\
0 \dagger \\
10\end{array}$ & $\begin{array}{r}0 \\
15 \\
15\end{array}$ & $\begin{array}{l}10 \\
15 \\
25\end{array}$ & $\begin{array}{l}2 \dagger \\
10 \dagger \\
12\end{array}$ & $\begin{array}{l}2 \\
7 \\
9\end{array}$ & $\begin{array}{r}4 \\
17 \\
21\end{array}$ \\
\hline
\end{tabular}

$\star$ Refers to index biopsies; $\mathrm{tp}<0 \cdot 001$; not every patient had both body and antral biopsies performed at repeat endoscopy.

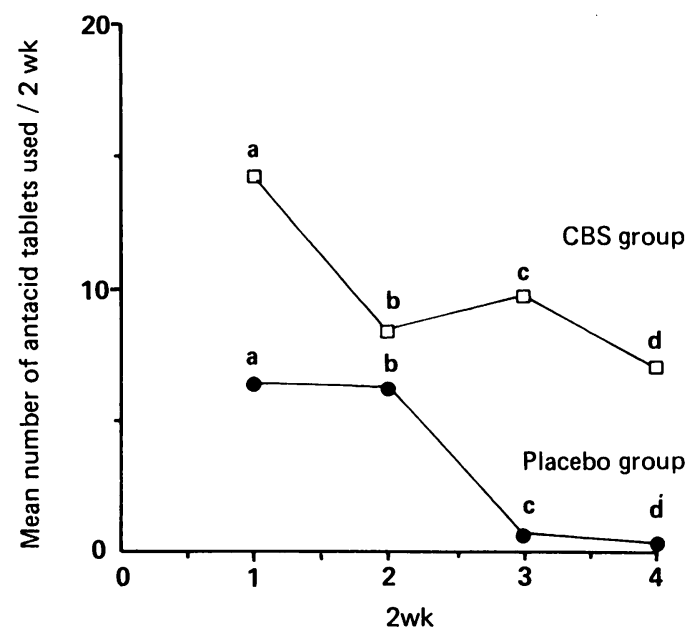

Figure 2: Use of antacids in patients without gastritis in their index biopsies, taking colloidal bismuth subcitrate or placebo. $a, b, c, d-n s$.

body biopsies and 23/50 (46\%) of index antral biopsies. There was good correlation between the presence of body gastritis and that of antral gastritis - only four patients had antral gastritis without body gastritis while all 19 patients with body gastritis also had antral gastritis. Helicobacter like organisms were present in 19/49 $(39 \%)$ of index body biopsies and $20 / 50(40 \%)$ of index antral biopsies. There was concordance between the presence or absence of Helicobacter like organisms in the body and in the antrum in $43 / 48(90 \%)$ of cases.

There was good correlation between histological gastritis in the body and/or antrum and the presence of Helicobacter like organisms. Twenty two of 23 patients (96\%) with histological gastritis were positive for these organisms while all $22(100 \%)$ with organisms in either their body or antral biopsies had histological gastritis.

\section{REDUCTION IN INFLAMMATORY SCORES} (TABLE III)

Overall, 16 of $44(36 \%)$ repeat gastric body biopsies and 14 of $46(30 \%)$ repeat antral biopsies showed a reduction in inflammatory scores over the study period. There was no difference between the colloidal bismuth subcitrate group and the placebo group in the numbers of patients showing improvement. If only the patients with gastritis in their initial biopsies were considered, however, more patients in the colloidal bismuth subcitrate group showed improvement in their antral biopsies compared with the placebo group $(\mathrm{p}<0.001)$. No significant difference was seen for body biopsies.

\section{RESOLUTION OR DEVELOPMENT OF GASTRITIS}

Of 10 patients in the colloidal bismuth subcitrate group with histological gastritis in their index body or antral biopsies (or both), resolution of gastritis (defined as absence of gastritis in both the body and antral biopsies at repeat gastroscopy) occurred in five (50\%). In contrast, none of 12 patients with initial histological gastritis in the placebo group showed resolution of their gastritis $(p<0.025)$. Of the 25 patients without 
histological gastritis in their index biopsies, repeat biopsies showed gastritis in five (20\%) (two of 16 in the colloidal bismuth subcitrate group compared with three of nine in the placebo group: NS).

\section{SUPPRESSION OF HELICOBACTER LIKE ORGANISMS}

Eight of nine patients in the colloidal bismuth subcitrate group who were positive for Helicobacter like organisms in their body or antral biopsies became negative on repeat biopsy. In the placebo group, in contrast, all 12 patients who had Helicobacter like organisms in their index biopsies retained their organisms on repeat biopsy $(\mathrm{p}<0.001)$. One other patient initially positive for organisms was not biopsied on repeat endoscopy.

PATIENT COMPLIANCE AND DROP OUTS Fifty of the 51 patients completing the trial took more than $82 \%$ of the prescribed medication while one patient took $72 \%$ of the prescribed tablets. Twenty two patients (11 from each group) were excluded from analysis for the following reasons: increasing symptoms necessitating withdrawal from the study (six:three from each group), defaulted follow up (six), intercurrent illness (three), poor compliance (three), gall stones demonstrated on ultrasound (three), administrative error (one).

\section{Discussion}

Previous therapeutic trials on non-ulcer dyspepsia have given inconsistent results. Some studies, for example, showed that cimetidine, ${ }^{11-14}$ ranitidine, ${ }^{15}$ or pirenzepine, ${ }^{16}{ }^{17}$ were superior to placebo in symptom relief. Other studies, however, showed no benefit for cimetidine ${ }^{18}$ or pirenzepine. " Differences in diagnostic criteria may account for these conflicting results. For example, dyspepsia has been variously defined as: epigastric pain, ${ }^{18}$ ulcer-like dyspepsia, ${ }^{12} 16$ epigastric or retrosternal pain or discomfort that was usually related to meals, ${ }^{15}$ or any pain, discomfort or nausea referable to the upper alimentary tract not precipitated by exertion and not relieved by rest. ${ }^{11}$ In one study patients with a previous history of ulcer disease were included ${ }^{12}$ while another study relied mainly on endoscopic rather than clinical criteria for diagnosis. ${ }^{13}$ Patient populations in these various studies may therefore have been different.

We feel that a definition of non-ulcer dyspepsia that is too broad may give rise to a heterogeneous study population consisting of different subgroups of subjects with different underlying pathophysiological mechanisms. A stricter definition may result in a more homogeneous patient population. We have therefore selected only patients whose pains were upper abdominal and strictly food related. ${ }^{19}$ Such pains may perhaps be more likely to originate from the stomach, possibly from gastritis. It has been shown that histological gastritis and Helicobacter pylori occur in approximately half of all patients with non-ulcer dyspepsia. ${ }^{67}$ Colloidal bis- muth subcitrate has been shown to eradicate Helicobacter pylori and improve histological gastritis $^{3-5}$ and symptoms ${ }^{20}$ in non-ulcer dyspepsia. The present study on non-ulcer dyspepsia patients with and without histological gastritis is therefore of interest.

In common with other workers we found little correlation between endoscopic and histological assessment of mucosal inflammation. ${ }^{21}$ Endoscopic appearances at the index and follow up endoscopies did not correlate with symptoms.

Most patients reported improvement of symptoms irrespective of treatment or of initial endoscopic or histological findings. Patient response to colloidal bismuth subcitrate varied, however, depending on whether or not histological gastritis and/or Helicobacter like organisms were present in their index gastric biopsies. More patients with histological gastritis became asymptomatic taking colloidal bismuth subcitrate compared with placebo, and their antacid consumption was reduced in three of four study periods. Concurrent with the improvement in symptoms, there was a greater prevalence of resolution of histological gastritis and reduction in the inflammatory scores of antral mucosa in the colloidal bismuth subcitrate group. The proportion of patients in whom Helicobacter like organisms were suppressed was also greater in the colloidal bismuth subcitrate group when compared with patients taking placebo.

On the other hand, patients who did not have gastritis in their index gastric biopsies did not benefit from colloidal bismuth subcitrate therapy. For this subgroup of patients, neither antacid usage nor the proportion of patients becoming symptom free was influenced by whether colloidal bismuth subcitrate or placebo was taken.

Patients with non-ulcer dyspepsia fall into two groups depending on the presence or absence of histological gastritis. We have shown that these two groups differ in their response to treatment with colloidal bismuth subcitrate. This may explain the conflicting results of previous treatment trials in non-ulcer dyspepsia. Our demonstration that the majority of patients reported improvement of symptoms regardless of therapy emphasises the need for a placebo group in therapeutic trials in non-ulcer dyspepsia. Our finding that symptoms paralleled changes in gastric histology and the occurrence of Helicobacter like organisms when histological gastritis was present suggests that the gastritis may be the cause of symptoms. In patients who did not have gastritis, the cause of symptoms remains unclear.

As our patients were not stratified at entry into the trial for the presence or absence of gastritis, the present findings therefore should ideally be confirmed by a further trial in which patients are stratified for gastritis. Our results are in agreement with those of Rokkas et al, ${ }^{20}$ however, and suggest that patients with non-ulcer dyspepsia and histological gastritis benefit from therapy with colloidal bismuth subcitrate.

The authors would like to thank Gist-Brocades for their support and for supplying the trial medication. This study was presented to the Autumn Meeting of the British Society of Gastroenterology, September 1988 
1 Hojgard L, Matzen P, Christoffersen P. Gastritis - a clinical entity? Scand F Gastroenterol 1987; 22 [suppl 128]: 90-3.

2 Marshall BJ, Warren JR. Unidentified curved bacilli in the stomach of patient with gastritis and peptic ulceration. Lancet 1984; i: $1311-4$.

3 Tytgat GNJ, Rauws E, Lagenberg W. The role of colloidal bismuth subcitrate in gastric ulcer and gastritis. Scand $\mathcal{F}$ Gastroenterol 1986;21 [suppl 122]: 22-9.

4 Marshall BJ, Armstrong JA, Francis GJ, Nokes NT, Wee SH. Antibacterial action of bismuth in relation to campylobacter Antibacterial action of bismuth in relation to campylobacter
pyloridis colonization and gastritis. Digestion 1987; 37 [suppl pyloridis col
2]: $16-30$.

5 Rauws EAJ, Langenberg W, Houthoff $\mathrm{HJ}$, Zanen HC, Tytgat GNJ. Campylobacter pyloridis associated chronic active antral gastritis. A prospective study of its prevalence and the effect of anti-bacterial and anti-ulcer treatment. Gastroenterology 1988; 94: 33-40.

6 Rathbone BJ, Wyatt JI, Worsley BW, et al. Systemic and local antibody responses to gastric Campylobacter pyloridis in non-ulcer dyspepsia. Gut 1986; 27: 642-7.

7 Rokkas T, Pursey C, Uzoechina E, et al. Campylobacter pylori and non-ulcer dyspepsia. Am F Gastroenterol 1987; 82: $1149-$ 52.

8 Manning AP, Thompson WG, Heaton KW, Morris AF. Towards positive diagnosis of the irritable bowel. Br Med $\dot{\mathcal{F}}$ 1978; $2: 653-4$.

9 Kang JY, Yap I, Guan R, Lim TC. Chilli ingestion does not lead to macroscopic gastroduodenal mucosal damage in healthy subjects. $\mathcal{F}$ Gastroenterol Hepatol 1988; 3: 579-82.

10 McNaulty CAM, Gearty JC, Crump B, et al. Campylobacter pyloridis and associated gastritis: investigator blind, placebo controlled trial of bismuth salicylate and erythromycin ethylsuccinate. $\mathrm{Br}$ Med 7 1986; 2: 645-9.
11 Talley NJ, McNeil D, Hayden A, Piper DW. Randomized, double-blind, placebo-controlled, cross over trial of cimetidine and pirenzepine in non-ulcer dyspepsia. Gastroenterology 1986; 91: 149-56.

12 Kleveland PM, Larsen S, Sandvik L, et al. The effect of cimetidine in non-ulcer dyspepsia. Scand $\mathcal{f}$ Gastroenterol 1985; 20: 19-24.

13 Nesland AA, Berstad A. Effect of cimetidine in patients with non-ulcer dyspepsia and erosive prepyloric changes. Scand $\mathcal{F}$ non-ulcer dyspepsia and erosive
Gastroenterol $1985 ; 20: 629-35$.

14 Johannessen T, Fjosne U, Kleveland PM, et al. Cimetidine responders in non-ulcer dyspepsia. Scand $\mathcal{f}$ Gastroenterol 1988; 23: 327-36

15 Saunders JHB, Oliver RJ, Higson DL. Dyspepsia: incidence of non-ulcer disease in a controlled trial of ranitidine in general practice. $B r M e d \mathcal{F} 1986 ; 1: 665-8$.

16 Dal Monte PR, D'Imperis N, Accardo P, Daniotti S Pirenzepine in non-ulcer dyspepsia. A double-blind placebo controlled trial. Scand f Gastroenterol 1982; 17 [suppl 72] 247-50.

17 Hradsky M, Wikander M. Effect of pirenzepine in the treatment of non-ulcer dyspepsia. A double-blind study. Scand F Gastroenterol 1982;17 [suppl 72]: 251-2.

18 Nyren O, Adami HO, Bates, S, et al. Absence of therapeutic benefit from antacids or cimetidine in non-ulcer dyspepsia. NEngl F Med 1986; 314: 339-43.

19 Bonnevie O. Future research - methodological aspects. Scand 7 Gastroenterol 1987; 22 [suppl 128]: 114-6.

20 Rokkas T, Pursey C, Uzoochina E, et al. Non-ulcer dyspepsia and short-term De-NOL therapy: a placebo controlled trial with particular reference to the role of Campylobacter pylori. Gut 1988; 29: 1386-91.

21 Whitehead R. Morphological aspects of duodenitis. Scand $\mathcal{F}$ Gastroenterol 1982; 17 [suppl 79]: 80-3. 